\title{
The Influence of Bio-Sociology and Behavioral Factors on Thai Adult Mortality in the Northeastern Community of Thailand
}

\author{
Nantawan Intachat \\ Graduate School of Public Administration, Burapha University. Chonburi, Thailand \\ (Email: n_intachat@hotmail.com)
}

\begin{abstract}
The purpose of this study was to investigate the influence of bio-sociological and behavioral factors on mortality. The area of study was Wang Namkheo District, Nakhon Ratchasima Province. A two-stage stratified random sampling method was employed, using interview forms. Samples were 200 households with a total population of 881 persons (674 persons alive and 207 persons dead). Statistics were generated using Logistic Regression Analysis. The study revealed that factors influencing adult mortality were in biological factors: age and gender; and in bio-sociological factors: marital status; in health behavioral factors: exercise, areca nut chewing and alcohol consumption. All factors enabled a prediction of mortality with variation of $30.6 \%$. The factors which have positive effects on mortality were: age, gender, marital status, exercise, areca nut chewing and alcohol consumption.
\end{abstract}

Keywords: Bio-Sociological Factors, Behavioral Factors, Thai Adult Mortality, Logistic

Regression Analysis, Wang Namkheo District

\section{Introduction}

\subsection{The Rationale and Significance of the Problems}

In this globalization era, the gap between the rich and the poor widens dramatically, as is rate of mortality which continues to differ for developed and developing countries. The same could be said about age, gender, marital status, geographical terrain and behavior. WHO (2005a) stated that over the past few years, it found a widening in the differences while the causal factors stemmed not only from biological factors. A study made by Hobcraft, McDonald and Rutstein (1984) indicates that age was a significant factor affecting mortality. In a longitudinal study, age is an indicator of development through the passage of time, whether age-wise, disease-wise or health-wise. Age therefore represents physical change as well as change through the social experience. Therefore, whether it is a concept in epidemiology, with Makeham's theory having a similar concept, that when age increases, the hazard of death for the elderly is greater than for youth. The study revealed another major biological factor, namely, gender, which is usually explained by occupational hazard, and being more exposed to environmental hazard. It was further explained that due to biological fundamentality at birth that males are more at risk from perinatal death than females (Dublin, Lotka and Spiegelman, 1949:129). Apart from the biological factor, the germicidal development factor is also significant, for example, in the case of tuberculosis and malaria becoming resist to drugs. It was found that non-communicable diseases also affect worldwide mortality while infectious diseases are still of concern. Moreover, death and illness are also dependent on social factors, where it is found that educational level also affects knowledge on health behavior (WHO: 2005a). A World Health Report 2005 (WHO: 2005b) stated that health is affected by lifestyle and genetic factors and that the best way to improve health is to improve behavior and to give the right information and education on health care (WHO: 2006).

Thailand is facing a major problem of high medical expenses but low return on health benefits. The population is still facing illness and death from preventable causes, such as AIDS, traffic accidents and various chronic illnesses. Moreover, it is found that health care accessibility is still inadequate and lacks 
service quality. The cost of health care has changed tremendously over the past two decades, with health care expenses increasing from $3.8 \%$ of GDP in 1980 to $6.14 \%$ in the year 2005 (Ministry of Public Health: 2007b).

A study on the burden of diseases of the Thai population between the years 1999-2004 of the International Health Policy Development Office, Ministry of Public Health (2006) found that age was a factor indicating population risk. Youth were faced with a mortality risk due to improper behavior. For gender, it was found that males had increased risk of death by violence and by careless behavior than females. Marital status also divided people into different types of mortality risks. The study found that the third rank in risk factors for males were: alcohol consumption, unsafe sex and smoking. A study into the causes of death in Thailand in the year 2000 revealed that the major cause of death for people age 15-44 years is infectious disease, with AIDS as the main cause, followed by external causes, such as traffic accidents, suicide and homicide; whereas for the age group 45-59 the principle causes of death changed to chronic diseases and incommunicable diseases: cancer and hypertension. The causes of chronic diseases stem from hypertension and stroke as these diseases bear a relationship to individual health care behavior, especially exercise, emotional stress and unsuitable food consumption (Chooprapawan, et al., 2000).

The behavior and lifestyle of modern Thais could readily be summed up as: inappropriate food, over-eating, lack of exercise, luxurious living and a harried lifestyle, etc. (Chindawattana, 2003; Ministry of Public Health, 2006) resulted in an increased rate of chronic diseases, such as diabetes, hypertension, and cardiovascular diseases. In addition, between the years 1988 - 1997 it was found Thais consume twice as much alcoholic drink (Ministry of Public Health, 2007b), and today Thais are at risk of consuming chemicals, chemical residues in plants, vegetables, and other food, causing them to be at risk from chronic illnesses and cancer (Chindawattana, 2003). The result of the study would assist in formulating specific health policy which resolves the health problem. In this instance, even though the area understudy was small scale, by using it to explain a larger scale under the same context, better coverage could be obtained than by using a foreign context.
This research focused on whether the biological factor of age, gender, ability in activity of daily live (ADL), the social factor of marital status, and the behavioral factor of exercise, areca nut chewing, smoking, and alcohol consumption had an impact on mortality. These factors might influence mortality, and if so, how. It could not be undertaken on a large-scale basis as there are great differences in the factors of geography, race, migration and several other factors concerned. I therefore conducted research on a small-scale society which has less limitations in the previous differentials and could depict biological, social and behavioral factors, namely Wang Namkheo District, Nakorn Ratchasima Province. It has an area of approximately $1,129,996$ square meters, being a new area elevated to the status of district in the year 1996. The majority of the population were migrants from different societies, spoke different languages and had different cultures. The natives have the characteristics of an ethnic hill-tribe minority group and have a different culture and lifestyle from the migrants. This affected not only their lifestyle and existence, but also affected well-being, mortality and causes of death.

\section{2. rtheastern Region and Wang Namkheo District}

The Northeastern Region has the largest area in Thailand with the largest population as well (approximately 21 million). It is well-known for its drought, and is thereby unsuitable for cultivation, while it also floods. There is irregular income and poverty with the highest out-migration rate in the country. In 1930, the mortality rate was very high, and even as far as the years 2005 - 2006, it still had the second highest mortality rate when compared to other regions (6.95/per 1,000 population), lower than only the northern region $(10.28 / 1,000$ population) (Ministry of Public Health, 2007b). Besides, it was found that most of the adult population died as a result of noncommunicable diseases, with cardiovascular disease and accidents, respectively (National Statistics Office, 2007) being dominant causes. It was found that the northeastern people tend to use chemicals, chemical fertilizers and pesticides in order to increase agriculture productivity. (Sirindhorn Anthropology Center, Public Organization, 2001). 
An important province in the northeastern region from the past to present, and sometimes known as "The Gateway to the Northeast", is Nakhon Ratchasima province. The population in the year 2007 was approximately 2.5 million, and it was found that the adult mortality rate was rather high with a crude death rate of about $5.54 \%$ in the year 2002, being the third highest ranking of the country (Ministry of Public Health, 2003). During the years $2002-$ 2006 the crude death rate was between 4.5-5.8 persons/1,000 population. The major causes of death in the year 2006 were infectious disease, non-infectious disease and death from external causes, respectively (Nakhon Ratchasima Public Health Office, 2007).

\section{3. eoretical Background of Adult Mortality}

Studies on the different causes of death in adults usually focus on variables of race, gender, socio-economic status and marital status as well as the time and causes of death. Differences are usually classified by social class. Socio-demographic research on the different causes of death in the past tended to explain and focus on the accuracy and quality of data and error of measurement rather than conceptual development. The theoretical principle led to a comprehensive conceptual framework for the study on the differentials in mortality which started to become of significant interest only recently (Adler, et al., 1994; Hummer, 1996; Preston and Taubman, 1994; Sickles and Taubman, 1997). There is no new theory on mortality because the studies focused on biological concepts while biodemographers gave priority to lifespan (Carey, 1997; Vaupel and Carey, 1993). Most of the studies focus on age as a basic variable to explain the relationship with death and other biological factors, as could be seen in the work of Olshansky, et al. (1997), which had revised Gompertz's Law of Mortality.

With regard to the conventional approaches to mortality, the study on demography into the different causes of death during the first stage was a focus on disparity among races, such as blacks and whites. Therefore the studies on the underlying causes of death were studies finding risk factors, such as smoking, food consumption and hormone differentials, all of which make males more at risk from ischemic heart disease than females.

\section{4. ta and Material}

This study was a cross-sectional analysis, employing secondary data from the death report as a sampling framework. The populations under study were adults aged over 15 years, using the framework from the death report of the Ministry of Public Health during 2002-2006. A two-stage stratified random sampling was used at sub-district and village levels, with data collected from every household reporting death during 2002-2006. Data were collected from 200 households with a total population of 881 persons (674 persons alive and 207 persons dead). Statistics were generated using Logistic Regression Analysis, which was employed a model for predicting the probability of an event. In this study, the event was death during the study period, and the event had a binomial distribution characteristic: death and survival. Therefore the equation of the probability of the event $(\mathrm{P}=$ probability) under study was a Logistic Response Function (Agresti, 2002; Vanichbuncha, 2005).

\section{Data Analysis}

The first step, according to the assumption of logical analysis, is that all variables under study were checked and formulated into appropriate measurement scales. The four variables in behavior factors were recoded into dichotomous form. The primary data indicated the distribution of data which were classified into age group, gender, socio-economic characteristics and behavior. Table 1 shows distribution of the above data.

\begin{tabular}{|l|c|c|c|c|}
\hline \multirow{2}{*}{ Variables } & \multicolumn{2}{|c|}{ Death } & \multicolumn{2}{c|}{ Survival } \\
\cline { 2 - 5 } & Number & Percent & Number & Percent \\
\hline
\end{tabular}




\begin{tabular}{|c|c|c|c|c|}
\hline \multirow[t]{2}{*}{ Variables } & \multicolumn{2}{|c|}{ Death } & \multicolumn{2}{|c|}{ Survival } \\
\hline & $\begin{array}{l}\text { Number } \\
(\mathrm{n}=207)\end{array}$ & Percent & $\begin{array}{l}\text { Number } \\
(\mathrm{n}=674)\end{array}$ & Percent \\
\hline \multicolumn{5}{|l|}{ Biological Factors } \\
\hline \multicolumn{5}{|l|}{ 1) Age Group } \\
\hline $15-19$ & 3 & 4.2 & 69 & 95.8 \\
\hline $20-24$ & 7 & 10.6 & 59 & 89.4 \\
\hline $25-29$ & 6 & 6.5 & 86 & 93.5 \\
\hline $30-34$ & 16 & 19.8 & 65 & 80.2 \\
\hline $35-39$ & 12 & 13.6 & 76 & 86.4 \\
\hline $40-44$ & 12 & 15.6 & 65 & 84.4 \\
\hline $45-49$ & 14 & 19.4 & 58 & 80.6 \\
\hline $50-54$ & 13 & 25.0 & 39 & 75.0 \\
\hline $55-59$ & 16 & 31.4 & 35 & 68.6 \\
\hline $60-64$ & 9 & 27.3 & 24 & 72.7 \\
\hline $65-69$ & 19 & 37.3 & 32 & 62.7 \\
\hline $70-74$ & 17 & 40.5 & 25 & 59.5 \\
\hline $75-79$ & 19 & 54.3 & 16 & 45.7 \\
\hline$>80$ & 44 & 63.8 & 25 & 36.2 \\
\hline \multicolumn{5}{|l|}{ 2) Gender } \\
\hline Female & 83 & 19.5 & 343 & 80.5 \\
\hline Male & 124 & 27.5 & 327 & 72.5 \\
\hline \multicolumn{5}{|c|}{ 3) Ability in Activity of Daily } \\
\hline Living & & & & \\
\hline No & 22 & 66.7 & 11 & 33.3 \\
\hline Yes & 185 & 21.8 & 663 & 78.2 \\
\hline \multicolumn{5}{|l|}{ Social Factors } \\
\hline \multicolumn{5}{|l|}{ 4) Marital Status } \\
\hline Single & 15 & 8.4 & 163 & 91.6 \\
\hline Married & 135 & 32.5 & 281 & 67.5 \\
\hline Divorced & 6 & 54.5 & 5 & 45.5 \\
\hline Widowed & 48 & 36.9 & 82 & 63.1 \\
\hline Don't Know/no answer & 3 & 2.1 & 143 & 97.9 \\
\hline \multicolumn{5}{|l|}{ 5) Education } \\
\hline Illiterate & 1 & 2.0 & 48 & 98.0 \\
\hline Literate & 206 & 24.8 & 626 & 75.2 \\
\hline
\end{tabular}




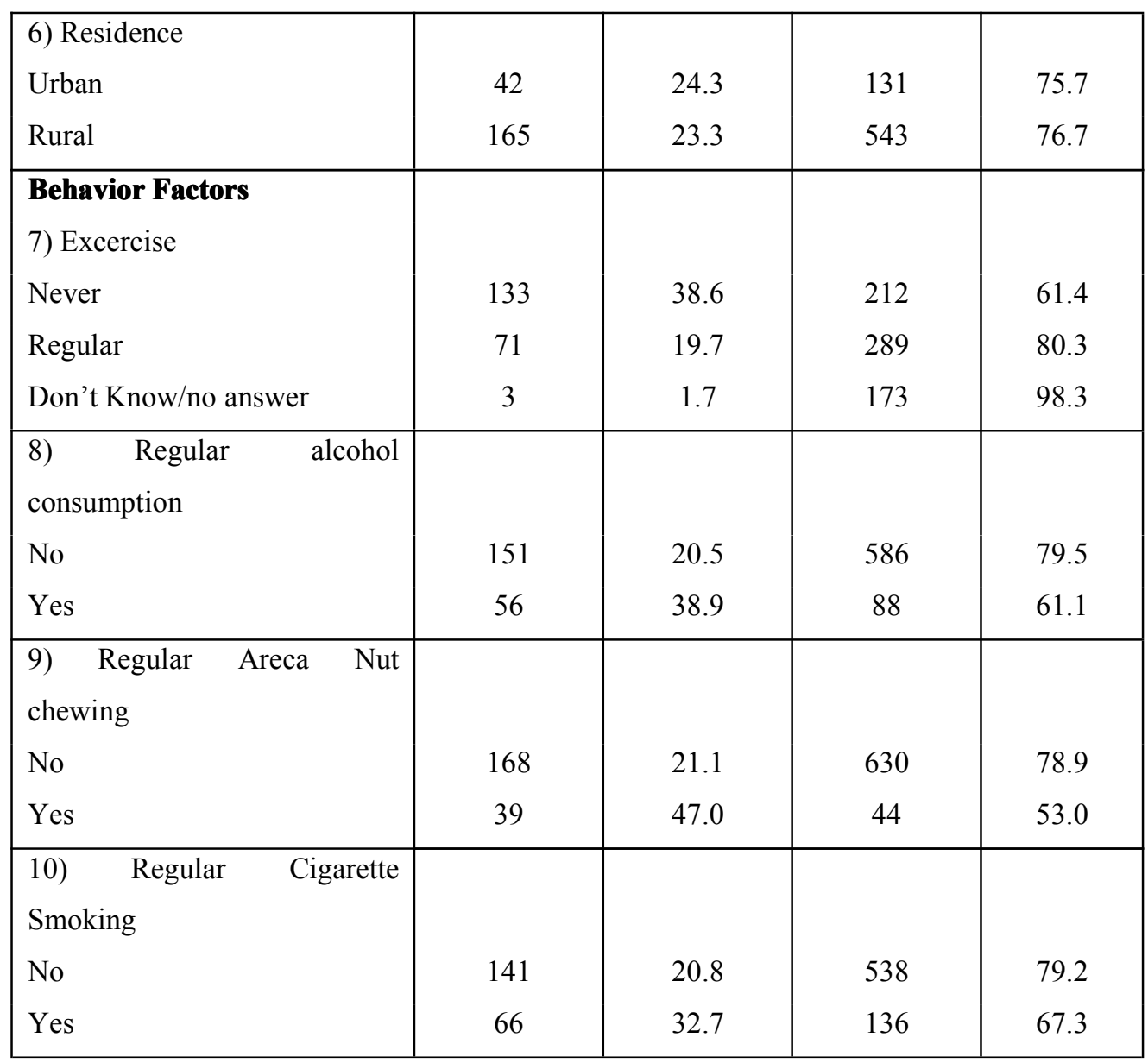

Table 1: Characteristics of the Population of Wang Namkheo District, Nakhon Ratchasima Province, classified by biological socio-economic and behavioral factor of "death" and "survival."

Table 1 divided the sample into 2 groups: "death" and "survival", with 207 "deaths" and 674 "survivals." The result showed that females had a higher proportion of survival than males, more people in the "death" category were not able to perform daily living activities more than in the "survival" category. With regard to education, those who died were not better educated than those who survived. There was little difference in dwelling areas between the two groups, with the majority living in rural areas. Under "exercise" it was found that those who exercised regularly were less likely to have died. With regard to those addicted to alcohol, areca nut chewing and smoking, the result was similar; namely, those who died consumed twice as much. Overall, those who drink alcohol were twice as likely to have died compared to those who survived. Data on the non-consumers' level revealed that those in the "survival" category were twice as numerous as those in the "death" category. Non-smokers had four times the probability of surviving.

\section{Influence of Socio-Biological and Behavioral Factors on Death}

The multi-collinearity was tested and the Logistic Regression Analysis result is illustrated in Table 2. 


\begin{tabular}{|l|r|}
\hline \multicolumn{1}{|c|}{ Factor } & \multicolumn{1}{c|}{ Exp (B) } \\
\hline Age & $1.049^{* * *}(.006)$ \\
\hline Gender & $2.270^{* * *}(.234)$ \\
Male (1) & $1.889^{*}(.321)$ \\
\hline Marital Status & $1.044(.408)$ \\
Married (2) & $1.919 * * *(.196)$ \\
Divorced/Widowed & $9.367 *(1.138)$ \\
\hline Exercise (3) & $1.344(.258)$ \\
\hline Areca Nut Chewing (4) & $2.057 * *(.257)$ \\
\hline Cigarette Smoking (5) & $1.511(.166)$ \\
\hline Alcohol Beverage Drinking (6) & $.0070(.478)$ \\
\hline Interaction (Cigarette Smoking*Areca Nut Chewing) & \\
\hline Constant & \\
\hline
\end{tabular}

Table 2: Co-efficient value, Standard Error, Probability Value of "dying" Exp (B) and the Level of Significance of Logistics Regression classified according to probability of "survival" of the adult population in Wang Namkheo District, Nakhon Ratchasima Province.

LogLikelihood $=660.704$, Model Chi-square $=165.556, \mathrm{df}=9, \mathrm{~N}=814, \mathrm{R}^{2}=.306$

$$
\text { Note: } \quad * \mathrm{p}<0.05, * * \mathrm{p}<0.0, * * * \mathrm{p}<0.001
$$

Reference: (1) female, (2) single, (3) no exercise, (4) no chew, (5) no smoke, (6) no drink

The study showed that factors which influenced mortality were: 1) biological factors : age and gender; 2) social factor: marital status; 3) health behavioral factors: exercise, areca nut chewing and alcohol consumption, all factors predicting a death rate death of 30.6\%. From Table 2 above, the factors having positive effects on mortality were: age, gender, marital status, exercise, areca nut chewing and alcohol consumption. In comparing the probability of dying or surviving (death=1, survival=0) when other factors remain constant, when age increased, the probability of dying increased, and males were 2.3 times more at risk of death than females; married individuals were 1.9 times more likely to die than those who were single, while divorced and widowed have the same probability of dying as those who were single. People who did not exercise were 1.9 times more at risk of death than those who did. Areca nut chewers were 9.4 times more liable to die than those who did not, and regular alcohol drinkers were 2.1 times more at risk of death than non-drinkers. Age was an important variable in representing biological factors. Death rates reflected physical changes and social influences (Hobcraft, Menken and Preston, 1982). When age increases, the

hazard of death in older people was greater than in younger people (Makeham, 1860). Moreover, age is also an influential factor for incidences of disease and death (Daengsupa, 1998). The study also found that another major biological factor was gender. It has been explained that the reason why males were more at risk of death than females is because of their higher exposure to danger from occupational and environmental hazards. There was an explanation of the biological factor by birth that males are more at risk of death than females (Dublin, Lotka and Spiegelman, 1949; Davanzo, Butz and Habicht, 1983).

Socio-economic factors that are underlying causes of death are: education, income and occupation (Sorlie, Backlund and Keller, 1995). This study found that married, divorced and widowed people were more at risk from death than the single. It could be explained by the concept that people tend to select healthy partners to marry, known as "health selection".

With regard to health behavior, it was found that the behaviors that strongly affect health were: smoking, alcohol consumption and 
exercise (Institute of Medicine, 2001). Grant and Dawson (1997) found that alcohol consumption was a major problem in American adults. It was found that over $40 \%$ started drinking before 15 years of age, and the age a person started to drink would determine his or her lifetime health. Illness or injury as a result of alcohol consumption would also depend on the quantity and period of drinking. A person who had been longer drinking was more prone to hypertension, cardiac arrhythmia, myocardial and stroke. There was a risk of esophagus, mouth, neck, vocal cord, large intestines and anus cancer. Regular heavy drinking could cause hepatitis, cirrhosis of the liver and liver disease. Moreover, the drinker would be at increased risk from traffic accidents, falls, firearms, and drowning. There would also be the prospect of assault, suicide, violence, child and sexual abuse (Institute of Medicine, 2001). It was found that beer consumption for Thais has increased tremendously. During the years 1988-1997 alcoholic beverage consumption has increased twofold (Ministry of Public Health, 2007b).

A regular areca nut chewer was 9.4 times more likely to die than a non chewer -- more than an alcohol drinker. It was explained that chewing areca nuts is an ancient tradition found in Asian countries. In Thailand, it is still commonly found in rural areas. Areca nut chewing caused oral cavity cancer. Continuous chewing of areca nuts will cause irritation to the oral cavity tissues which would later turn into cancer. Moreover, while chewing areca nuts, some people both chew tobacco and/or smoke. In Taiwan, it was found that the main cause of oral cavity cancer is areca nut chewing. In Thailand, the study of Chatrchaiwiwatna (2006) found that areca nut chewing caused periodontitis and increased the probability of losing teeth. In this study it was also found that about $90.4 \%$ of areca nut chewers live in rural areas.

The lower-educated and lower income people tended to have unhealthy behaviors such as being addicted to smoking and found it difficulty to quit (Hummer, Rogers and Eberstein, 1998). At the same time, it is found that the four risk-related behaviors of smoking, alcohol consumption, sedentary lifestyle such as a desk job and obesity, were related to lower-educated people (Lantz, et al., 1998; Bucher and Ragland, 1995), and liking to smoke, and being obese with little or no exercise. However, it was revealed that lowereducated people were usually elderly, short in stature and were addicted to smoking. But this study, similar to the research made by Peppas, et al. (1993), found that the differences in educational level has different effects on mortality, with the mortality rate reduced positively with level of education, but the reduction was higher in the case of highlyeducation people. It was particularly interesting to note that the wide gap in death rate came from differences in the education level. However, Preston and Elo (1995) found that education inequality has a very wide gap for males, but a narrower gap in females at labor age groups. The Ministry of Public Health conducted many campaign to encourage reduction, refraining from and quitting drinking and smoking, such as the "not driving while under intoxication", "not driving after imbibing", "safety-belt on", and "protection helmets for motorcyclists" campaigns. All projects aimed to reduce the rate of untimely death from unsafe sex, drink driving, assault and various other crimes. The stated factors caused the Thai population who had died from "external causes" to have a lower life expectancy at birth because of death from all other causes, with an average of approximately 44 years (male $=41.5$ years, female $=47.23$ years). And they also lost life expectancy at birth of approximately 28.37 years (Intachat, 2004). T he Ministry of Public Health found that the age of drinkers and smokers had reduced from past, indicating that the population at risk started younger. This study confirmed that improper behavior affects longevity. So, if the people have good health, it would be one way to prevent the Thai population from untimely death or from other preventable causes as stated above.

Thailand is currently facing a problem of high medical expenses, but the population were still confronted with sickness and death from preventable causes which arise mostly from improper behavior, such as traffic accidents, which cause untimely demise. A population's "health" reflects the cause of death, and health also reflects the health care and medical service accesibility, as well (Chindawattana, 2003; Ministry of Public Health, 2007b). The mortality of the Thai population reflects several social problems, namely: 1) death of a family member is one of the factors that causes disintegration of the family; 2) death of a 
person of labor age economically affects family, community and society; 3 ) death of an infant, a child and a youth would affect future labor age population; 4) both high and low mortality rates reflect the medical and public health service system, nutritional, sanitation, environment, personal and family sanitation as well as the economic and social development plan, and; 5) death affected changes in the structure of population and number of population (Chooprapawan, et al., 2000).

\section{Conclusion}

This study confirmed that regular exercise will act as a barrier and will reduce the risk of death by up to twice as much as those who did not exercise. Change in behavior is crucial and should receive great priority for implementation to cover remote areas. Everybody should be given information on how to take care of their health and how to change improper behavior as well as be shown the benefits of the result, with emphasis in building a network of information and in changing the behavior of the people in community, village, district levels as well as the lifestyle, nutritional behavior, exercise and drug consumption by encouraging people to initiate projects that are suitable and possible for their lifestyle and interests since initiations by the authorities have been found to be unsuitable for people's lifestyles. Moreover, health care should start from infancy. In the same way, the use of narcotics has been widely known and acknowledged as affecting the mortality of the Thai population. In perusing related literature, it was found that areca nut chewing affects death, especially from oral cavity cancer. Therefore, I would like to propose the policy that people should be given information on how areca nut chewing would affect health. This should include education, public relations, and campaigns; and there should be further research with regard to the rate of areca nut chewing, starting age of use, and the risk of illness as a result of chewing. For remote areas, the accessibility to health care was rather difficult; and this is one of the reasons why it is not easy to promote health care for all ages. Policies should emphasize participation in behavioral change by giving information and education The benefits would be long-lasting and would cater to the lifestyle of the local community, for example, local games, folklore (such as walking on coconut shells), and Thai traditional massage. Finally, every health service - curative, heath promotion, rehabilitation, home visiting, and health education - must be imparted to the people. Health information can be disseminated through the community broadcasting towers or printed materials, by co-operation of health officers, health volunteers, household heads, monks and teachers, etc, and would help sustainable wellbeing. Research should study factors that may affect health and mortality as well as preventative measures and evaluation should be made after implementation. Then government and private sectors should emphasize health policy implementation in order to increase Thai life expectancy for a healthy and later death.

\section{KNOWLEDGEMENTS}

This article was a part of a research project on "The Mortality Differentials in the Urban and Rural of Thailand: A Case Study of Wang Namkheo District, Nakhon Ratchasima Province", and has been jointly funded by the TRF-CHF Research Grant for New Scholars of the Commission on Higher Education, Ministry of Education and the Thailand Research Fund. I would like to thank the Board of Directors for giving me the opportunity of making this research. Our sincere thanks also go to the Dean of the Graduate School of Public Administration, Burapha University for her kind promotion and support.

\section{References}

[1] Adler, N.E., Boyce, W. T., Chesney, M.A., Cohen, S., Folkman S., Kahn, R. L., and Leonard S. S. Socioeconomic status and health: The challenge of the gradient. American Psychologist, 1994, 49 (1): 1524.

[2] Agresti, A. Categorical Data Analysis. New York: Wiley-Interscience, 2002.

[3] Bucher, H.C. and Ragland, D.R. Socioeconomic indicators and mortality from coronary heart disease and cancer: A 22-year follow-up of middle-aged men. American Journal of Public Health, 1995, 85 (9):1231-1236. 
[4] Carey, J. R. What demographers can learn from fruit fly actuarial models and biology. Demography, 1997, 34 (1): 17-30.

[5] Chatrchaiwiwatana, S. Dental Caries and Periodontitis Associated with Betel Quid Chewing: Analysis of Two Data Sets. Journal of the Medical Association of Thailand, 2006, 89 (7): 1004-1011.

[6] Chindawattana, A. Health Reformation, Life Reformation and Social Reformation. Bangkok: Usa Publisher, 2003.

[7] Chooprapawan, C., Porrapakkham, Y., Jirawatkul, A., Poa-in, W. Report on Study on Causes of Death in Thailand, First Round. Bangkok: publisher not specified, 2000.

[8] Daengsupa, P. Epidemiology: Public Health Solutions in the Community of Prachuab Kirikhan. Prachuab Kirikhan: Prachuab Publisher, 1998.

[9] DaVanzo, J., Butz, W.P. and Habicht, J.P. How Biological and Behavioural Influnces on Mortality in Malaysia Vary during the First Years of Life. Population Studies, 1983, 37 (3): 381-402.

[10] Dublin, L., Lotka, A., Spiegelman, M. Length of life. New York : The Ronal Press Company, 1949.

[11] Grant, B.F. and Dawson, D.A. Age at onset of alcohol use and its association with DSM-IV alcohol abuse and dependence: Results from the national longitudinal alcohol epidemiologic survey. Journal of Substance Abuse, 1997, 10 (2): 163-173.

[12] Hobcraft, J. N., Menken, J. and Preston, S. Age, Period and Cohort Effects in Demography: A Review. Population Index, 1982, 48 (1): 4-43.

[13] Hobcraft, J.N., McDonald, J. W., Rutstein, S.O. Socio-economic factors in infant and child mortality: A cross sectional comparison. Population Studies, 1984, 38 (2): 193-223.

[15] Hummer, R. Black-White differences in health and mortality: A review and conceptual model. Sociological Quarterly, 1996, 37 (1): 105-125.

[16] Hummer, R., Rogers, R. and Eberstein, I. Sociodemographic differentials in adult mortality: A review of analytic approaches. Population and Development Review. 1998, 24 (3):

553-578.
[17] Intachat, Nantawan. Cause of Death in Thailand: Patterns and Differences. Unpublished doctoral dissertation .Faculty of Graduate Studies, Mahidol University, 2004.

[18] Institute of Medicine. Health and Behavior: The interplay of Biological and Societak Influnces. Washington, D.C.: National Academic Press, 2001.

[19] Lantz, P. M., House, J. S.,. Lepkowski, J.M., Williams, D.R., Mero, R.P., Chen, Jieming. Socioeconomic Factors, Health Behaviors, and Mortality Results From a Nationally Representative Prospective Study of US. Adults. Journal of the American Medical Association, 1998, 279 (21): 1703-1708.

[20] Ministry of Public Health. Provincial Health Surveys Analysis. Bangkok: Samcharoen Panich Publisher, 2003.

[21] Ministry of Public Health. Wang Namkheo District Information. [Online]. Available from: http://www.wnk.go.th.pho. [Accessed 2007 January 7], 2006.

[22] Ministry of Public Health. Mortality Situation of Thai Population 2005. Nonthaburi: War Veteran Organization Publisher, 2007a.

[23] Ministry of Public Health. Thai Public Health 2005-2007. Nonthaburi: War Veteran Organization Publisher, 2007b.

[24] Nakhon Ratchasima Public Health Office. Nakhon Ratchasima Annual Report, 2006. Nakhon Ratchasima : Nakhon Ratchasima Public Health Office Press, 2007.

[25] National Statistics Office. Report on Survey of Population Change 2005-2006. Bangkok: National Statistics Office Press, 2007.

[26] Olshanky, S. Jay, Bruce A. Carnes, Richard G. Rogers and Len Smith. Infectious diseases-New and ancient threats to world health. Population Bulletin, 1997, 52 (2): 1-48.

[27] Peppas, G., Queen, S., Hadden, W. and between socioeconomic groups in the United States, 1960 and 1986. New England Journal of Medicine, 1993, 329 (2): 103-115.

[28] Preston, Samual H.and Paul Taubman. Socioeconomic differences in adult mortality and health status. Washington, DC.: National Academy Press, 1994. 
[29] Preston, Samual H. and Elo, I.T. Are Educational Differentials In Mortality Increasing in the United States? Population Aging Research Center, University of Pennsylvania Working Paper Series No. 95-01, 1995.

[30] Sickles, Robin C. and Taubman, Paul. Mortality and morbidity among adults and the elderly. Handbook of Population and Family Economics. Amsterdam: Elsevier science, 1997, 1 (A).

[31] Sirindhorn Anthropology Center (Public Organization). Geography and the Thais' Way of Life. Bangkok: Amarin Publisher, 2001.
[32] Sorlie, P. D., Backlund, E. and Keller, J. B. US mortality by economic, demographic, and social characteristics: The National Longitudinal Mortality Study. American Journal of Public Health, 1995, 85 (7): 949-956.

[33] Vanichbuncha, K. Advanced Statistical Analysis with SPSS for Windows. Bangkok: Thammasarn Publisher, 2005.

[34] Vaupel J.W., Carey, JR . Compositional interpretations of medfly mortality. Science, 1993, 11 (2): 1666-1667.

[35] World Health Organization. Global forum for health research 2005. New York: ProBook Publishing Limited, 2005a.

[36] World Health Organization. World health report 2005. New York: Pro-Book Publishing Limited, 2005b.

[37] World Health Organization. Public health innovation and intellectual property rights, report of the commission on intellectual property right, innovation and public health. Geneva: World Health Organization Press, 2006. 